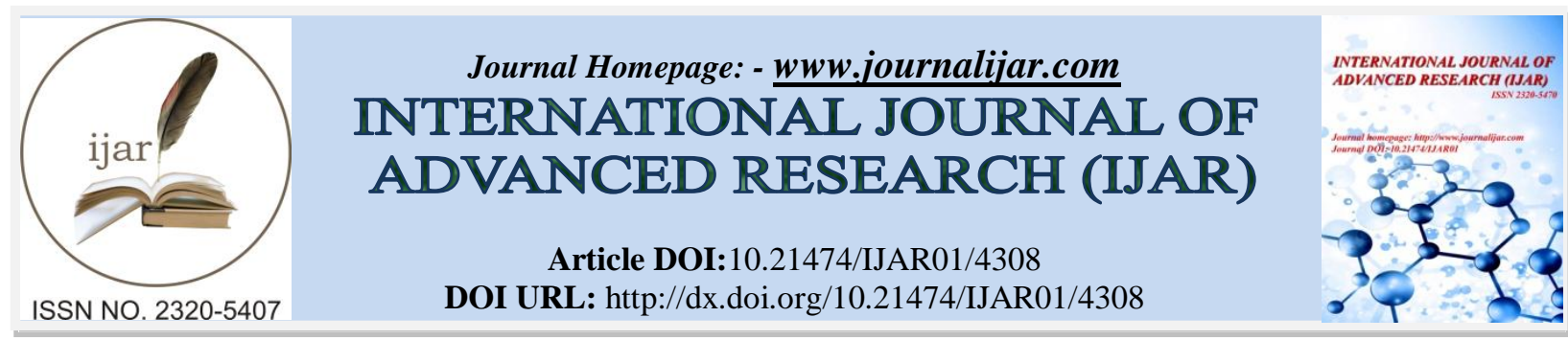

RESEARCH ARTICLE

\title{
DIFFICULTIES IN ANSWERING MULTIPLE CHOICE QUESTIONS AMONG UMM AL-QURA MEDICAL STUDENTS,MAKKAH, SAUDI ARABIA.
}

\section{Dr. Hassan AdnanBukhari ${ }^{1}$, Dr. Hatem Adel Sembawa ${ }^{1}$, Dr. Rani Abdullah AlSairafi ${ }^{1}$, Dr. Majdi Saleh} Alzahrani $^{2}$, Dr. Basam Zuhaer Sindi ${ }^{2}$ and Dr .Mohammed Saleh Dumyati ${ }^{2}$.

1. Assistant Professor, Umm Al-Qura University, College of Medicine, General Surgery Department, Makkah, Saudi Arabia.

2. Medical intern, Umm Al-Qura University, College of Medicine, Makkah, Saudi Arabia.

\section{Manuscript Info}

\section{Manuscript History}

Received: 20 March 2017

Final Accepted: 25 April 2017

Published: May 2017

Key words:-

Medical Education , MCQ, Social

Sciences .

\section{Abstract}

Multiple Choice Question ( MCQ ) is used in assessing and evaluating the educational process worldwide as well as medical schools in Saudi Arabia. The Study is cross-sectional study was carried out in 278 medical students at Umm Al-Qura University, Makkah, Saudi Arabia. Data was collected by using a "pre-tested" semi-structured questionnaire. The data were analyzed using SPSS Version 11 statistical. There are four main reasons that make MCQ exam difficult to students. There are aproblem in studying methods,problem in teaching technique,problem in the giving curriculum and problem in the language. Other difficulties in answering MCQ exam related to the way of questions include: problems in the content of thequestion, problems in the level of the exam, problems in answer options and problems in recalling.Also, the time given is insufficient or difficulties in time organization during exam one of main problems. There are some external problems such as separated answering sheet, anxiety symptoms, eating and sleeping before theexam.

Copy Right, IJAR, 2017,. All rights reserved.

Abbreviations and Symbols:-

MCQ: Multiple Choice Question

SPSS: statistical package for the social sciences

\section{Background:-}

Studying and memorizing is not enough when it comes to the word MCQ, there is a vagueness that makes the students confuse. 'Why I get low marks even when I study hard" a common phrase that strikes your ear after MCQs exams.

\section{Introduction:-}

Multiple Choice Question ( MCQ ) is a well-known tool utilized in assessing and evaluating the educational processworldwide. MCQs are aneasy,comprehensive and fast method to mark the tests and this is the reason why it's the preferred type of questions given to the students. 
The Multiple choice question (MCQ) formats is the most regularly used written assessment technique for such tests, because of its special positive psychometric characteristics, its long history of research evidence, its versatility in analysis most cognitive knowledge, its relative (apparent) ease to write, collect, administer and score, and its progressive use in the highest state examinations in medical education( 1,2) . Multiple choice questions are able to test a number of skills, such as understanding, reasoning, data interpretation and problem solving, in addition to the recall of factual knowledge. They are true, discriminatory, reproducible and cost-effective. In arelationship with other examination methods - such as oral, practical, essay examinations a very important element of the MCQ format is the possibility of its evaluation $(2,3)$. The classical pedagogical analysis of the MCQ uses the difficulty and discrimination indices, (4) but there are some alternate ways to assess test question value and validity using computer generated matrices (5).

In many branches, the academic performance is based usually on MCQ exams especially in the medical field.

Medical students go through MCQs during all the period of studying in their college and also postgraduation in license exams, residency exams etc.

Many obstacles have been a concern for the students in understanding and solving MCQs which led to poor grades and results despite the hard study.

Our focus is to determine the difficulties that face the medical students in Umm Al-Qura University and to set the possible solutions to resolve it.

\section{Objectives:-}

To determine the difficulties that face the Medical students to get high marks in MCQs exams and to set reasonable solutions to solve it.

\section{Methods and Material:-}

The present cross-sectional study was carried out in 278 medical students at Umm Al-Qura University, Makkah, Saudi Arabia. It includes 137 male students and 141 female students. The study population was done on medical college students from different classes and different educational level. These participated students were surveyed about the difficulties they face in answering Multiple Choice Questions (MCQs). The sample size was 278 college students. Data was collected by using a "pretested" semi-structured questionnaire. The questionnaire was pre-tested among a group of 5 medical college students in Umm Al-Qura University and was revised to enhance its clarity and comprehension. Data were collected after obtaining informed consent from the study subjects. The data were analyzed using SPSS Version 11 statistical.

\section{Results:-}

This study conducted among 278 medical students at Umm Al-Qura University including first to the sixth medical year aim to know the difficulties that face medical students in answering MCQs.

One of the reasons that make the MCQ exams difficult for the students is that they do not know the proper way to study the subjects for answering MCQs. According to this study, $36 \%$ of students agree that their way of studying do not fit the pattern of the exam. Other reasons which make the MCQ difficult are the teaching technique and giving curriculum, we found that $49.3 \%$ of the students they blame the methods used in teaching, as it is not efficient methods to do well in answering MCQ and $34.9 \%$ of students they think that the content of the exams is not related to the giving curriculum. The language is considered one of thedifficulties because the main language used in teaching is not the native language for the students, we found that $23.7 \%$ of students considered the language as abarrier for them to answer MCQs (figure 1 ). 


\section{Figure1. Effect of teaching and studying in answering MCQ}

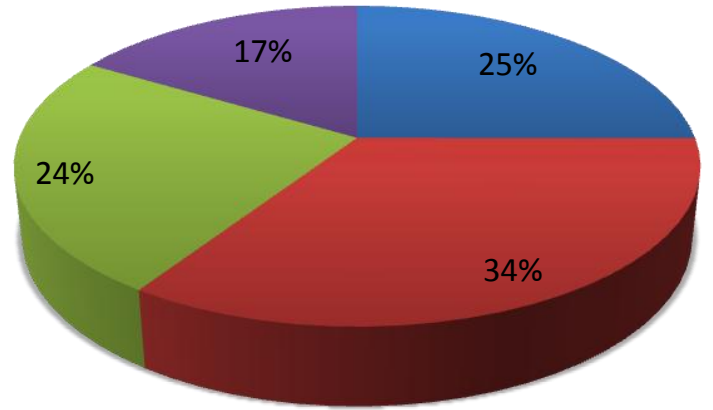

Problem in the studying methods

Problem in teaching methods.

Problem in the giving curriculum

Problem in the language

Other difficulties in answering MCQs exam related to the way of the questions in the exam and the time given ( figure 2,3 ). We found that $49.7 \%$ of students agreed that the contents of thequestion in MCQs exams are so long. Another problem is the level of the exams as $45.3 \%$ of students think that the level of exams is more advanced than what is expected. According to the options given in the answer of MCQs, 48.9\% found that options given are too similar to each other which cause confusion for them, while $60.8 \%$ think that the options consist of more than one correct answers. Also, we found that 59\% of students face difficulties in recalling the correct answer.

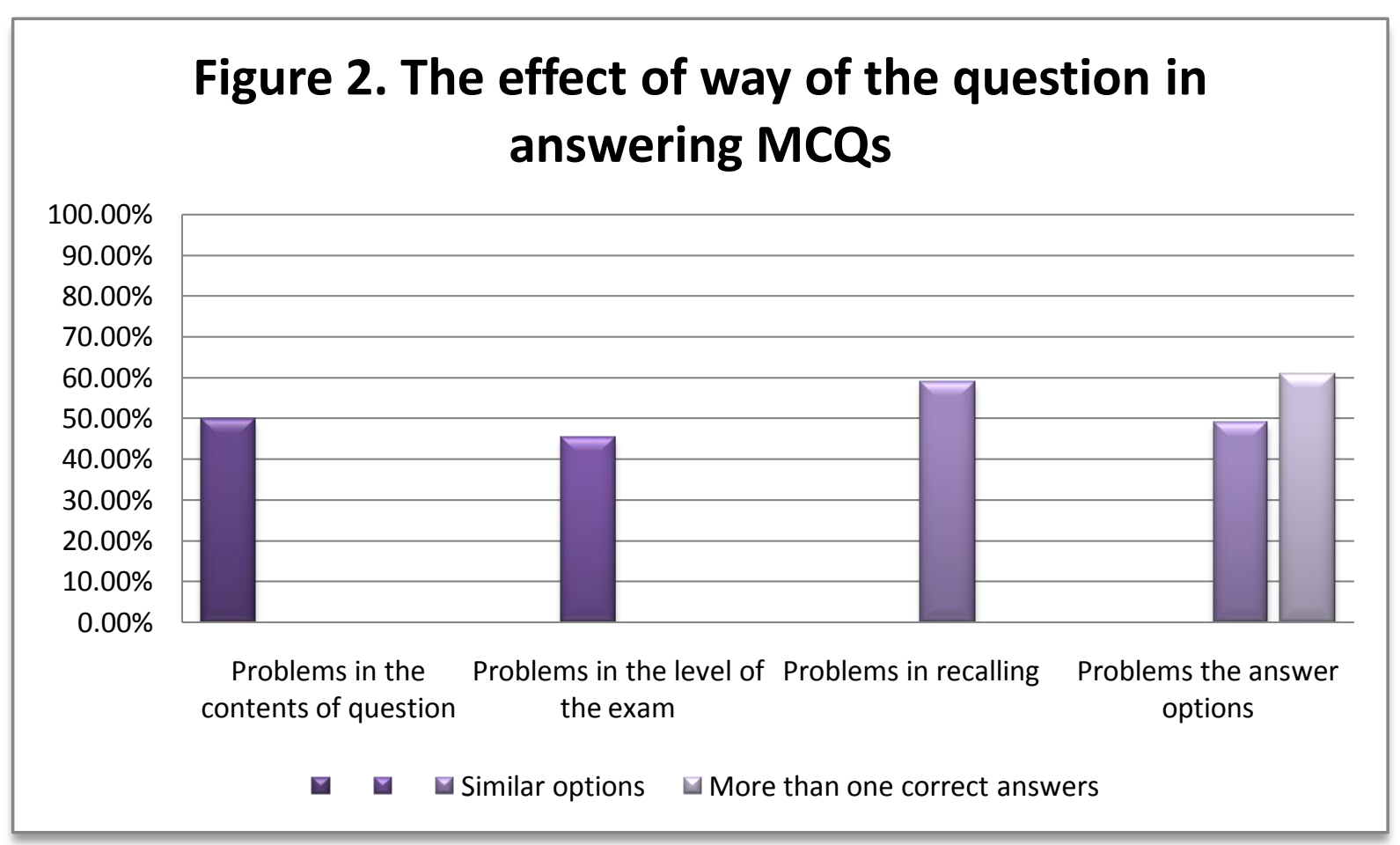


The time is one of the main problems in the exam as $60.1 \%$ of students find the time given for the exam is not sufficient and $60.8 \%$ of students have difficulties in organizing their time during answering the exam.

\section{Figure 3. Time problems}

QTime given for the exam is not sufficient $\quad$ Time organization problems

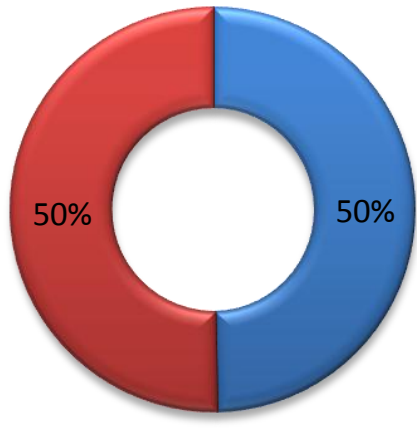

One of aproblem with MCQ exams is that the answering sheet is separated from questions sheet so $28.8 \%$ end up by non-compatible selection between answer and question sheets. We found also $42.8 \%$ of students experience anxiety symptoms like palpitation, sweating, shortness of breath and abdominal pain during the exam, and these symptoms affect negatively on $28.1 \%$ of students and $35.5 \%$ sometimes affect them.

Eating and sleeping are important factors that students need to take care of before exam, we found that $29.1 \%$ of students they do not sleep enough before the exam and 50\% of those students who do not sleep enough they do not focus well on the exam because they feel sleepy during the exam. About eating we found that $35.6 \%$ of students they do not eat before the exam and $38.8 \%$ of students think to feel hungry during the exam affect badly in answering ( figure 4 ).

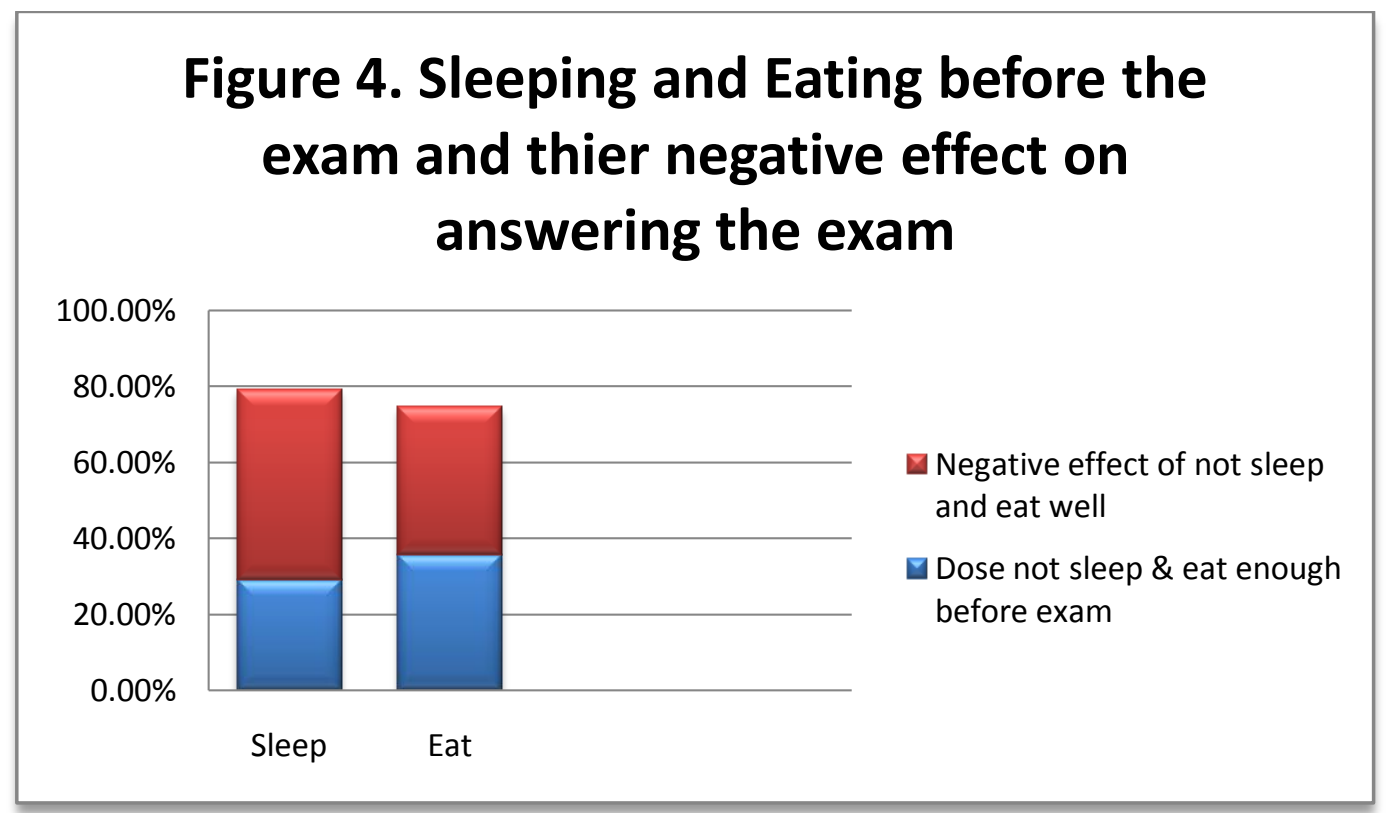


When we asked the students about which type of the exam they preferred we found only $15.5 \%$ of students they prefer essay exams more than MCQ exams. About the ideal numbers of the questions, we found that $69.4 \%$ of students think that the average numbers of total questions in MCQs are around 60 questions.

\section{Discussion:-}

Multiple Choice Question ( MCQ ) is used in assessing and evaluating the educational process worldwide as well as medical schools in Saudi Arabia. Medical students go through MCQs during all the period of studying in their college and also post- graduation in license exams, residency exams etc. Many difficulties facing him to get high marks. Our study aim is to determine the difficulties that face the medical students in Umm Al-Qura University and to set the possible solutions to resolve it.

The study shows that there are four main reasons that make MCQ exam difficult to students. There are: problem in studying methods (25\%),problem in teaching technique (34\%),problem in the giving curriculum (24\%) and problem in the language(17\%). Other difficulties in answering MCQ exam related to the way of questions include: problems in the content of question (49.7\%), problems in the level of the exam (45.3\%), problems in answer options and problems in recalling (59\%). Also, the time given is insufficient or difficulties in time organization during exam one of main problems. There are some external problems such as: separated answering sheet, anxiety symptoms, eating and sleeping before theexam.

During the study, we asked the student about which type of exam they preferred MCQs or essay exam and what the ideal average number of MCQs. In thesame study found at Greece shown $29 \%$ of the surgery questions were found to be inappropriate (too difficult or too easy) for medical students, interns, and foreign candidates, respectively. Specifically, surgery questions were significantly more inappropriate for interns than for candidates, and Internal Medicine questions were easier for interns than for students or foreign candidates at a statistically significant level (6) this study support the language barrier theory, as in our study estimated $23.7 \%$ of students considered the language as a barrier, on another handanother study in 2010 at Umm Alqura University in Saudi Arabia shown the English language skills were rated the second difficulty facing them in the first year (mean rank 3.95) (7)

Now we know the main problems, so we can start to solve it from university side by modifying teaching methods, clarifying the curriculum, using of native language for student and review the content of thequestion and answering option by drafting committee. And the main solve is from student side byfind aproper way to study the subject for answering MCQ and easily recalling in theexam, use time organization technique, use of relaxing exercise for anxiety symptoms and take care of eating and sleeping enough before the exam.

If all the above difficulties resolved every hardworking student will get high marks in MCQs exam.

\section{Conclusion:-}

This study we can use it results in all medical schools in Saudi Arabia as well as worldwide to compare between each university difficulties in answering MCQ. Also, we can increase the sample size and add different population from same university to assess the reality of this result.

\section{References:-}

1. Downing SM. Threats to the validity of locally developed multiple- choice tests in medical education: construct-irrelevant variance and construct under representation. Adv Health SciEduc Theory Pract 2002;7:235-241.

2. Schuwirth LW, van der Vleuten CP. Different written assessment methods: what can be said about their strengths and weaknesses? Med Educ 2004;38:974-979.

3. Auewarakul C, Downing SM, Jaturatamrong U, Praditsuwan R. Sources of validity evidence for an internal medicine student evaluation system: an evaluative study of assessment methods. Med Educ 2005;39:276-283. 
4. Sim SM, Rasiah RI. Relationship between item difficulty and discrimination indices in true/falsetype multiple choice questions of a para-clinical multidisciplinary paper. Ann Acad Med Singapore 2006;35:67-71.

5. DeSantis M, McKean TA. Efficient validation of teaching and learning using multiple choice exams. AdvanPhysiol Edu 2003;27:3-14.

6. VassilikiKostopoulou, MD, CsillaZafiriou, MD, John Lymveos, MD, ChrysanthiTrikka, MD,

7. SavvasToumanidis, MD. The Examination of Accreditation for Foreign Medical Graduates in Greece: Evaluation of the Multiple Choice Question Format Using Difficulty and Discrimination Indices. HOSPITAL CHRONICLES 2011; 6(2); 79-83.

8. H. Almoallim, S. Aldahlawi, E. Alqahtani, S. Alqurashi and A. Munshi Difficulties facing firstyear medical students at Umm Alqura University in Saudi Arabia. EMHJ 2010;16;1272-1277. 